\title{
Mechanical Properties of Chitosan-Starch Composite Filled Hydroxyapatite Micro- and Nanopowders
}

\author{
Jafar Ai, ${ }^{1}$ Mostafa Rezaei-Tavirani, ${ }^{2}$ Esmaeil Biazar, ${ }^{3}$ \\ Saeed Heidari $K^{2}$ and Rahim Jahandideh ${ }^{3}$ \\ ${ }^{1}$ School of Advanced Medical Technologies, Tehran University of Medical Sciences, Tehran, Iran \\ ${ }^{2}$ Proteomics Research Center, Faculty of Paramedical Sciences, Shahid Beheshty University of Medical Sciences, Tehran, Iran \\ ${ }^{3}$ Department of Biomaterials Engineering, Tonekabon Branch, Islamic Azad University, Tonekabon, Iran
}

Correspondence should be addressed to Esmaeil Biazar, e.biazar@tonekaboniau.ac.ir

Received 30 April 2011; Revised 4 July 2011; Accepted 4 July 2011

Academic Editor: Donglu Shi

Copyright (c) 2011 Jafar Ai et al. This is an open access article distributed under the Creative Commons Attribution License, which permits unrestricted use, distribution, and reproduction in any medium, provided the original work is properly cited.

\begin{abstract}
Hydroxyapatite is a biocompatible ceramic and reinforcing material for bone implantations. In this study, Starch-chitosan hydrogel was produced using the oxidation of starch solution and subsequently cross-linked with chitosan via reductive alkylation method (weight ratio (starch/chitosan): 0.38). The hydroxyapatite micropowders and nanopowders synthesized by sol-gel method (10, 20, $30,40 \% \mathrm{~W}$ ) were composited to hydrogels and were investigated by mechanical analysis. The results of SEM images and Zetasizer experiments for synthesized nanopowders showed an average size of $100 \mathrm{~nm}$. The nanoparticles distributed as uniform in the chitosan-starch film. The tensile modulus increased for composites containing hydroxyapatite nano-(size particle: 100 nanometer) powders than composites containing micro-(size particle: 100 micrometer) powders. The swelling percentage decreased for samples containing hydroxyapatite nanopowder than the micropowders. These nanocomposites could be applied for hard-tissue engineering.
\end{abstract}

\section{Introduction}

Hydroxyapatite $\left(\mathrm{HA} ; \mathrm{Ca}_{10}\left(\mathrm{PO}_{4}\right)_{6}(\mathrm{OH})_{2}\right)$ is a type of calcium phosphate that has extensive application in the healing of bones and teeth, due to its biocompatibility and similar composition to that of natural bone. Biodegradability and nontoxicity, especially mechanical properties, are important factors for scaffolds in hard-tissue engineering [1-5].

Chitosan has been proved and regarded as biodegradable noncytotoxic material which has some interesting biological activities [6-8]. Some of the recent studies, however, indicate that chitosan, with higher than $60 \%$ deacetylation degree, shows little amount of degradation and is not absorbed easily in-vivo [8]. Starch, an biodegradable biopolymer, is getting increasingly more attractive because of its renewability, biodegradability, and low cost. Starch-based polymers have recently been proposed as having great potential for applications in biomedical field as implant materials, drug delivery systems, and tissue engineering scaffolds $[9,10]$. In order to use it in temporary medical applications, such as temporary hard-tissue replacement, bone fracture fixation, and bone tissue scaffold, blends of starch with different materials such as ethylene-vinyl alcohol copolymer (SEVA) and poly (caprolactone) (SPCL) have been proposed [11-13]. Over the past 30 years, synthetic hydroxyl apatite and glass/ceramics have been developed and used in the medical field [14]. It is well known that when these bioactive ceramics are implanted in the body, spontaneously bond to living bone via an apatite layer deposited on their surface and is expected to confer a bone-bonding behavior and to improve the mechanical properties of these composites $[15,16]$. Starch/ethylene vinyl alcohol (SEVA-C) as scaffold showed unsuitable mechanical properties for bone engineering, but starch-based polymers are a potential alternative, especially when reinforced by bioactive bone-like $[17,18]$. In most biomedical applications, membranes are in direct contact with living tissues. Therefore, besides the usual mechanical characterization carried out in the dry state, new systems should also be subjected to test routines that 


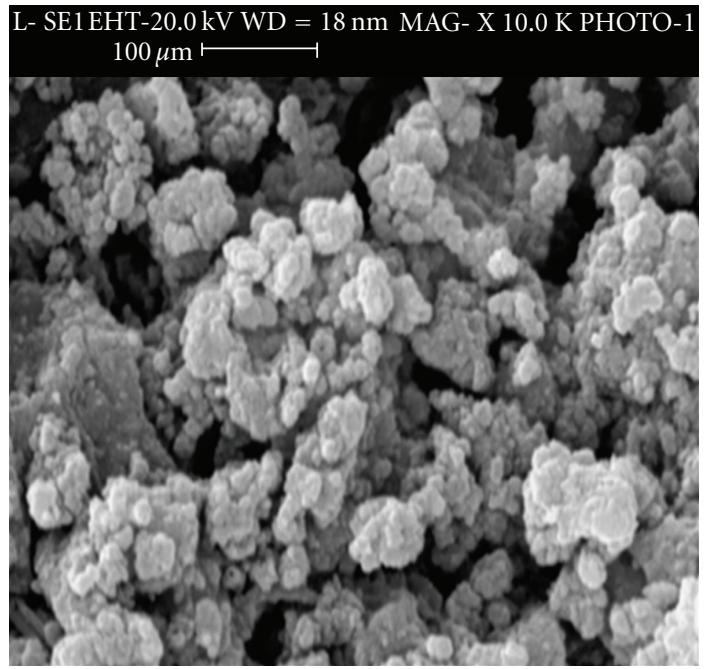

(a)

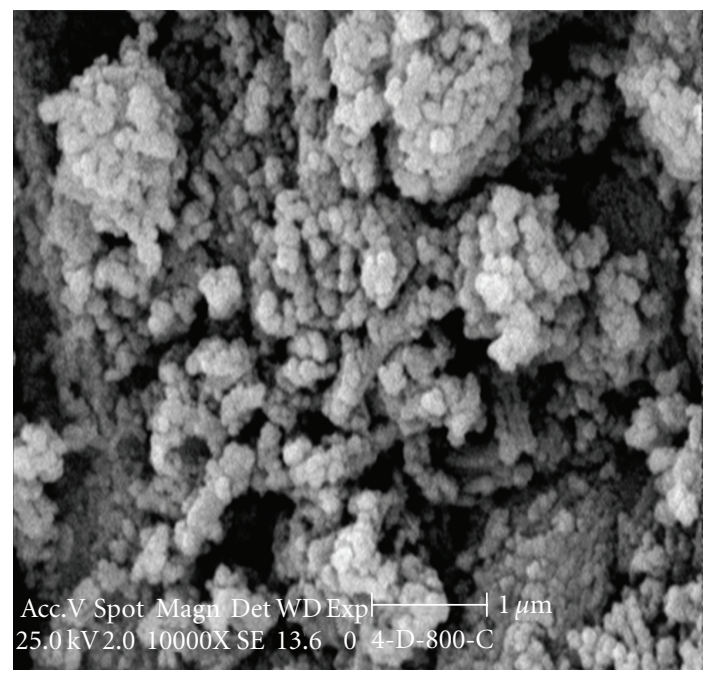

(b)

FIGURE 1: SEM micrographs of HAp nano- and micropowders (a) HAp micropowders (b) HAp nanoparticles (10000X).

allow for the evaluation of their mechanical performance in more realistic conditions [17-22]. In this study, the starchchitosan composites containing micro- and nanopowders were synthesized and investigated by mechanical analysis.

\section{Materials and Methods}

2.1. Materials. Chitosan (deacetylation degree 87\%), acetic acid, sodium hydroxide, sodium periodate (merk), $\mathrm{Ca}\left(\mathrm{NO}_{3}\right)_{2} \cdot 4 \mathrm{H}_{2} \mathrm{O}$ (Acros 99\%), $\mathrm{P}_{2} \mathrm{O}_{5}$ (Acros 99\%), HAP (sigma-aldrich; particle size: 60-180 micrometer), ethyl alcohol, PBS Solution, and deionized water.

2.2. Methods. The Hap nanopowder was prepared $(\mathrm{Ca} / \mathrm{P}$ molar ratio: 1.67$)$ using $\mathrm{Ca}\left(\mathrm{NO}_{3}\right)_{2} \cdot 4 \mathrm{H}_{2} \mathrm{O}$ and $\mathrm{P}_{2} \mathrm{O}_{5}$ by a simple sol-gel approach. A designed amount of phosphoric pentoxide was dissolved in absolute ethanol to form a

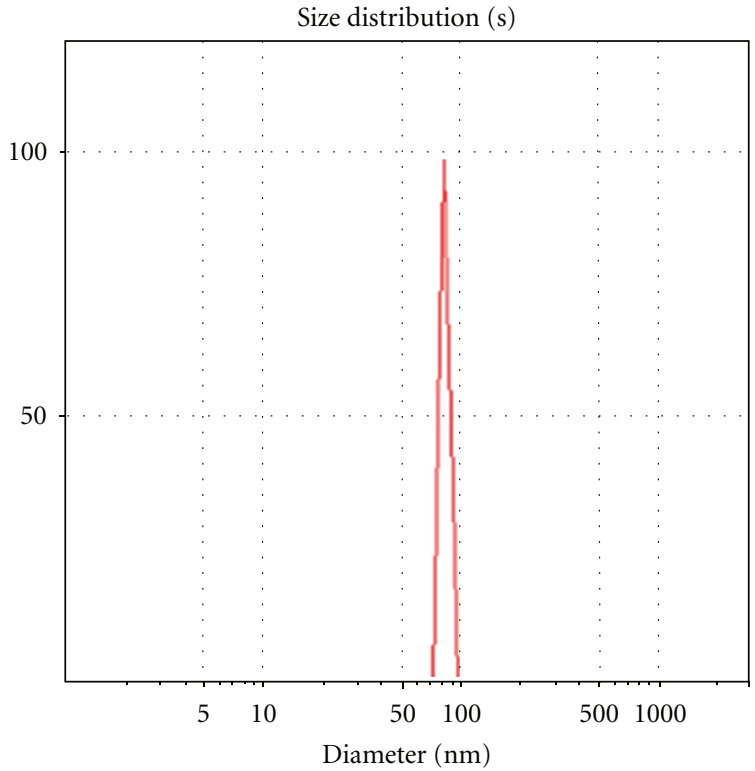

FIgure 2: Particle size distribution of HAP nanopowder in $10000^{\circ} \mathrm{C}$.

TABLE 1: Tensile modulus of starch-chitosan composites containing HAP micro and nanopowders. E1\% (elasticity modulus in $1 \%$ strain).

\begin{tabular}{lcc}
\hline HAP\% & $\begin{array}{c}\text { E1\% (Gpa) composite } \\
\text { containing HAP } \\
\text { micropowder }\end{array}$ & $\begin{array}{c}\text { E1\% (Gpa) composite } \\
\text { containing HAP } \\
\text { nanopowder }\end{array}$ \\
\hline 0 & 1.8 & 1.8 \\
10 & 3.4 & 3.8 \\
20 & 4.1 & 4.7 \\
30 & 5.1 & 5.5 \\
40 & 5.8 & 6.1 \\
\hline
\end{tabular}

$0.5 \mathrm{~mol} / \mathrm{L}$ solution. A designed amount of calcium nitrate tetrahydrate was also dissolved in absolute ethanol to form a $1.67 \mathrm{~mol} / \mathrm{L}$ solution. The mixture was stirred constantly for $24 \mathrm{~h}$ by a mechanical stirrer, allowing the reaction to complete at $800^{\circ} \mathrm{C}$. A transparent gel was obtained. The gels were individually heated at a rate of $5^{\circ} \mathrm{C} / \mathrm{min}$ up to $1000^{\circ} \mathrm{C}$ for $6 \mathrm{~h}$. The sintered powders were ball-milled at $100 \mathrm{rpm}$ to get fine powders.

Commercially obtained $\mathrm{Ca}\left(\mathrm{NO}_{3}\right)_{2} \cdot 4 \mathrm{H}_{2} \mathrm{O} \quad(0.01 \mathrm{~mol}$; Acros 99\%) and $\mathrm{P}_{2} \mathrm{O}_{5}$ ( $0.03 \mathrm{~mol}$; Acros 99\%) were poured into $10 \mathrm{~mL}$ of ethyl alcohol with the molar ratio of $10: 3$ (which is desired $\mathrm{Ca} / \mathrm{P}$ ratio for hydroxyapatite). This solution transformed into a gel after stirring slowly for $1 \mathrm{~h}$. The gel was then dried in an oven at $120^{\circ} \mathrm{C}$ in air for $15 \mathrm{~h}$ followed by subsequent heat-treating in stagnant air at $950^{\circ} \mathrm{C}$ for $12 \mathrm{~h}$. HAP powders were obtained with particle sizes of 100-150 nanometers by this sol-gel method. Oxidized starch was prepared according to the procedure described by Hermanson [23]. $4.65 \mathrm{~mL}$ oxidized starch was mixed with $20 \mathrm{~mL}(1 \% \mathrm{w} / \mathrm{v})$ of chitosan (weight ratio of 0.38 ). Then, the nanoparticles and microparticles in the 


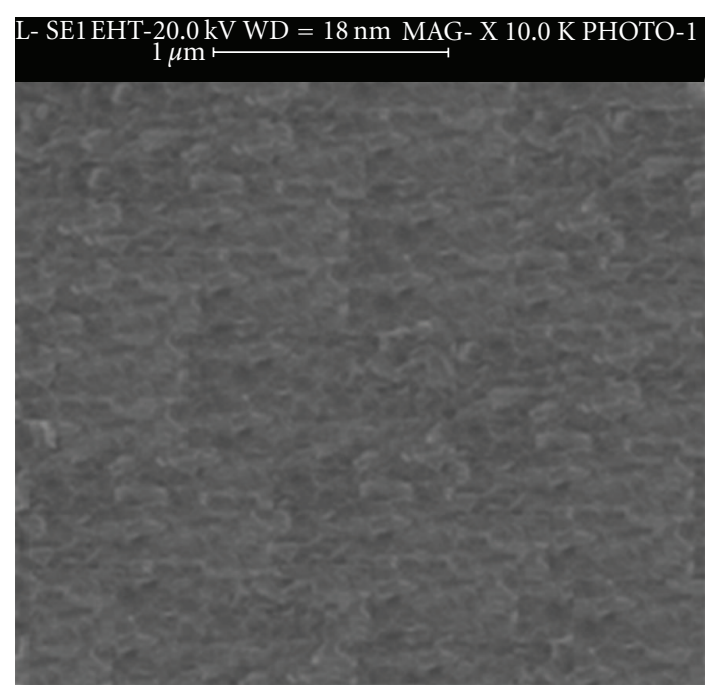

(a)

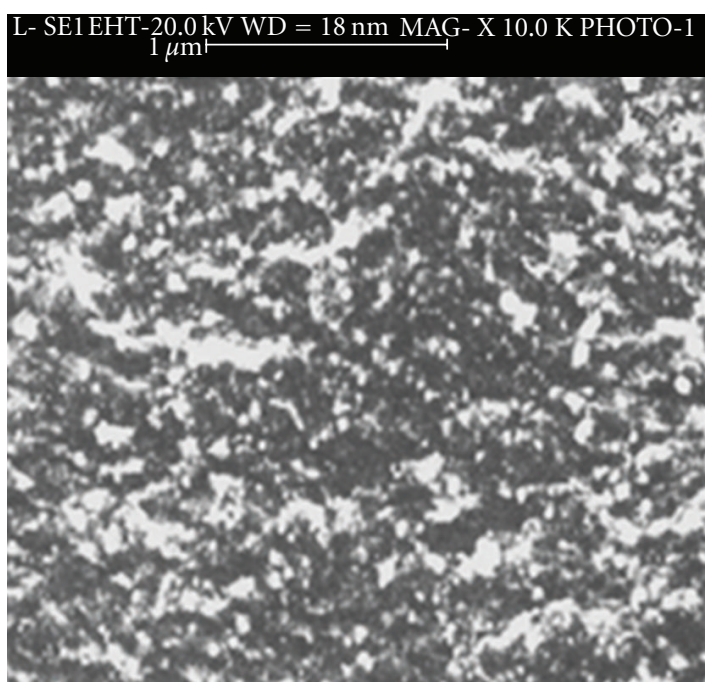

(b)

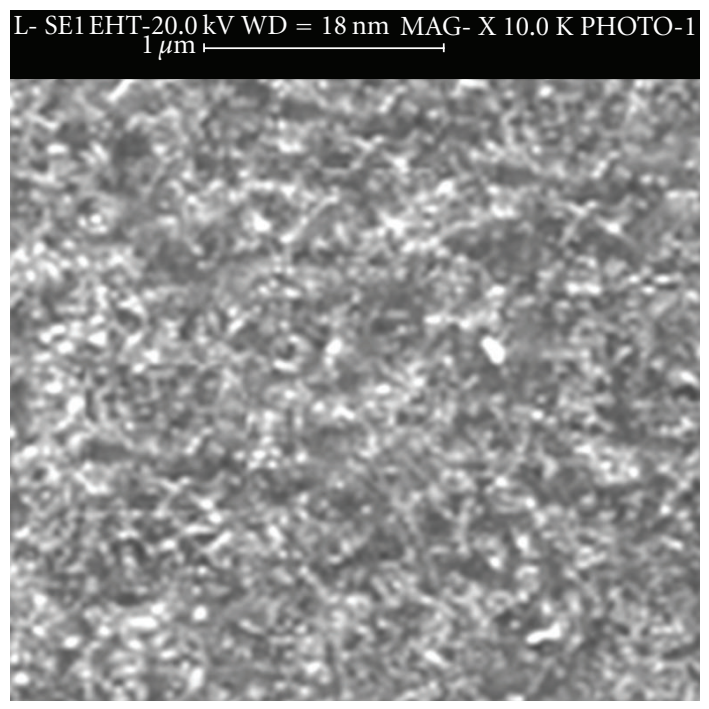

(c)

FIGURE 3: SEM micrographs of chitosan-starch/HAp nano- and microcomposite samples (a) chitosan-starch (b) chitosan-starch/HAp micro composite samples 30\% (w/w), (c) chitosan-starch/HAp nanocomposite samples 30\% (w/w).

different ratios were added slowly with vigorous stirring with the help of a mechanical stirrer at $3000 \mathrm{rpm}$. After addition of entire nanoparticles to the polymer solution, the resulting solution mixture was kept in a vacuum desiccator to remove the bubbles. Then, the mixture was heated in a water bath to evaporate water. The resulting slurry was poured into a glass petri dish and dried to make a film, keeping it in a vacuum oven at $60^{\circ} \mathrm{C}$ over night. Samples were washed several times with distilled water and then were incubated with aqueous sodium borohydride solution $(0.05 \%)$ for $1 \mathrm{~h}$ to reduce excess noncross-linked aldehyde groups and chitosan. After washing several times with distilled water, samples were allowed to be dried on the petri dishes at room temperature. The morphological characteristics and size of the samples were studied by Zetasizer ( 3000 HAS; Malvern Instruments Ltd, Malvern, UK), scanning electron microscopy (SEM)
(XL30; Philips, Eindhoven, Holland), and transmission electron microscopy (TEM) (CM200FEG; Philips). The tensile test of composite (membrane strips with $5 \mathrm{~mm}$ in width) in dry state was carried out with Instron Universal Mechanical Tensile Machine at room temperature using a crosshead speed of $1 \mathrm{~mm} / \mathrm{min}$ and $40 \mathrm{~mm}$ grip distance. The presented results are the mean values of five independent measurements. The swelling percentage of swollen samples was measured after reaching equilibration point $(3 \mathrm{~h})$ where no change in weight of samples was observed. This percentage could be calculated according to the following:

$$
\% S=\frac{(\mathrm{Mw}-\mathrm{Mi})}{\mathrm{Mi}} \times 100,
$$

where $\% S$ is the percentage of swelling, and $\mathrm{mi}$ and $\mathrm{mw}$ are the weight of the samples before immersion and after 


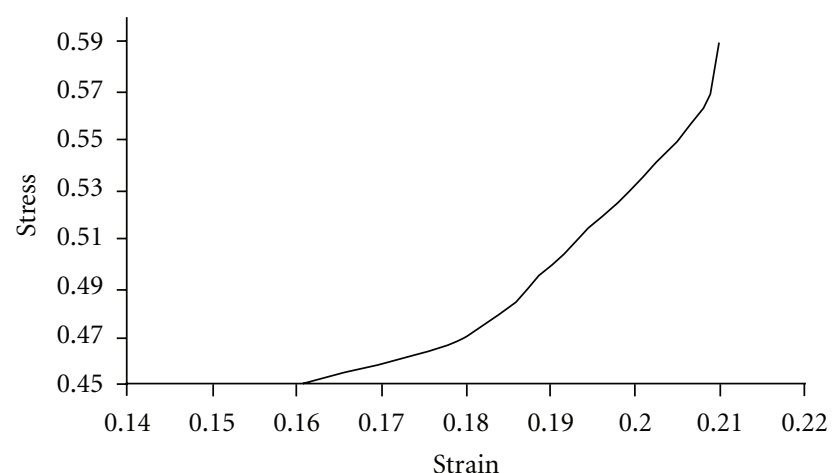

FIGURE 4: Stress-strain curve obtained for starch-chitosan with weight ratio of 0.38 .

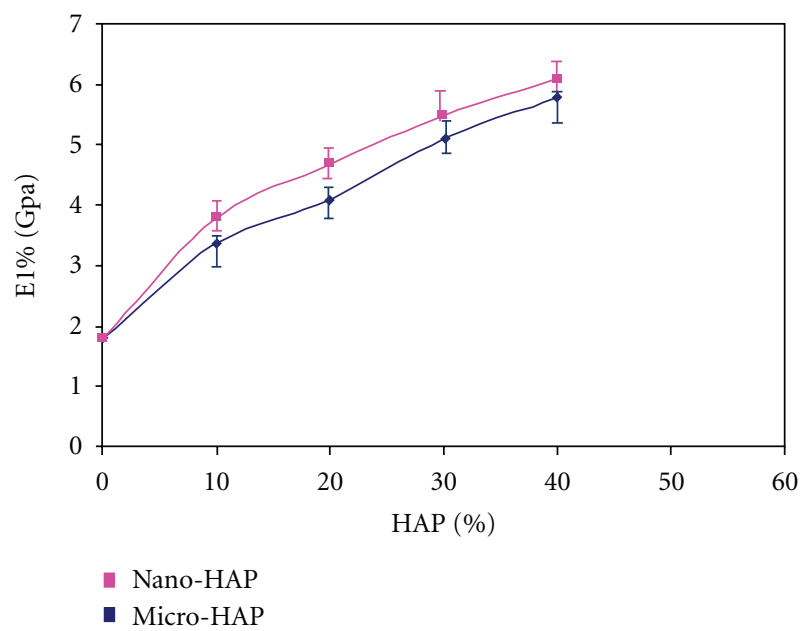

Figure 5: Tensile modulus of starch-chitosan composites containing HAP micro- and nanopowders. (The tensile modulus of these composites was increased gradually with increasing filler percentage. Error bars indicate the maximum and minimum values for 4-6 samples measured.)

TABle 2: Swelling percentage of starch-chitosan composites containing HAP micropowders.

\begin{tabular}{lcc}
\hline HAP\% & $\begin{array}{c}\text { Swelling \% composite } \\
\text { containing HAP } \\
\text { micropowder }\end{array}$ & $\begin{array}{c}\text { Swelling \% composite } \\
\text { containing HAP } \\
\text { nanopowder }\end{array}$ \\
\hline 0 & 0.135 & 0.135 \\
10 & 0.1 & 0.09 \\
20 & 0.08 & 0.05 \\
30 & 0.06 & 0.03 \\
40 & 0.04 & 0.02 \\
\hline
\end{tabular}

equilibration period in physiological buffer solution (PBS), respectively.

\section{Results and Discussion}

3.1. Microscopic Results. SEM images of powders with magnification 10,000X are shown in Figures $1(\mathrm{a})$ and 1(b).

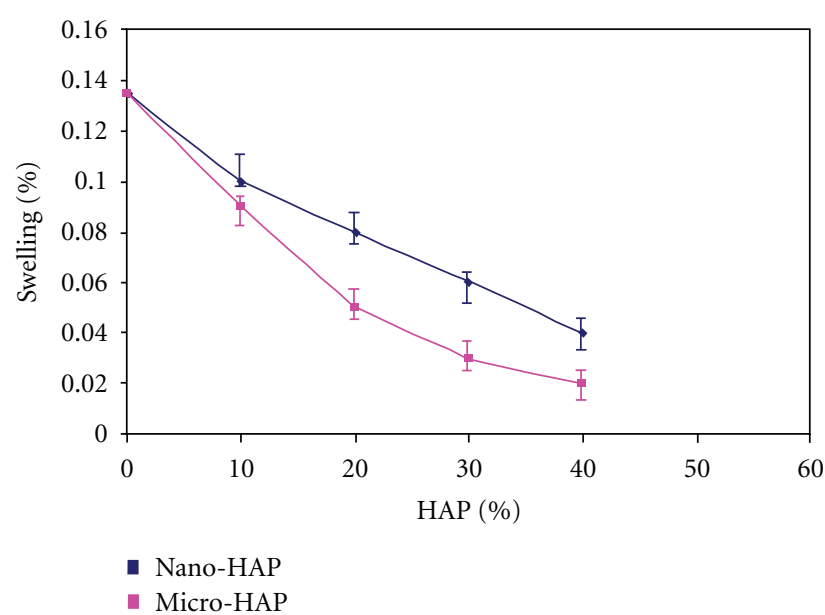

Figure 6: Swelling Percentage of starch-chitosan composite containing HAP micro- and nanopowders. The swelling percentage of composites with HAP micro and nanopowders was decreased gradually with increasing filler percentage, but swelling percentage of composites with HAP nanopowders is lower than composites with HAP micropowders.

Figure 1(a) shows particle sizes about $100 \mu \mathrm{m}$ for commercial particles, and spherical particles formed in sol-gel method showed particle sizes to be about $100 \mathrm{~nm}$. Considering the SEM image, it seems that the agglomerates were sufficiently dispersed in the Zetasizer testing conditions. The Zetasizer experiments for the dispersed particles in its own conditions showed particle sizes with an average size of $100 \mathrm{~nm}$ (Figure 2). Figure 3 shows SEM micrographs of chitosanstarch/HAp nano- and microcomposite samples $(30 \% \mathrm{~W})$. The figures indicated uniform distribution of nanoparticles in the polymer, but it is not for microparticles.

3.2. Mechanical Test. Figure 4 illustrates stress-strain curve for chitosan-starch copolymer. This figure shows that strain increases with stress increasing. Table 1 and Figure 5 show tensile modulus of composites containing HAP micro- and nanopowders. It could be observed that tensile modulus of these composites increases from 1.8 to $5.8 \mathrm{Gpa}$ with the increasing HAP micropowders from 0 to $40 \%$ and from 1.8 to $6.1 \mathrm{Gpa}$ with increasing of HAP nanopowders from 0 to $40 \%$.

3.3. Swelling Test. Figure 6 and Table 2 show that swelling percentage of composites containing HAP powders decreases with increasing HAP percentage, and also values obtained from results show that swelling percentage for composites containing HAP nanopowders is less than this percentage for composites containing HAP micropowders.

\section{Conclusions}

In this study, starch-chitosan hydrogel were produced by oxidation of starch solution and subsequently crosslinked with chitosan via reductive alkylation (weight ratio 
(starch/chitosan): 0.38) and then filled with HAP nanopowders produced by sol-gel method and micropowders (10, 20, 30, $40 \% \mathrm{~W})$. The SEM and Zetasizer analysis showed morphology and size average of nanoparticles. The results obtained from SEM images showed uniform distribution of nanoparticles in the chitosan-starch composite. The tensile modulus of composites containing the HAP micro- or nanopowders was increased gradually with increasing filler ratio, but strength of composite with the HAP micropowders was lower than the HAP nanopowders due to more uniform distribution of nanoparticles in the polymeric matrix. The swelling percentage of composites with the HAP micro- or nanopowders was decreased gradually with filler percentage increasing, but swelling percentage of composite with the HAP nanopowders was lower than the composite with the HAP micropowders that could be due to more uniform distribution of nanoparticles in polymeric matrix and barrier for water penetration in membrane. These composite containing nanopowders could be used for hard tissue engineering.

\section{References}

[1] B. Cengiz, Y. Gokce, N. Yildiz et al., "Synthesis and characterization of hydroxyapatite nanoparticles," Colloids and Surfaces A, vol. 322, no. 1-3, pp. 29-33, 2008.

[2] M. J. Larsen and S. J. Jensen, "Solubility, unit cell dimensions and crystallinity of fluoridated human dental enamel," Archives of Oral Biology, vol. 34, no. 12, pp. 969-973, 1989.

[3] M. J. Finkelstein and G. H. Nancollas, "Trace fluoride and its role in enamel mineralization," Journal of Biomedical Materials Research, vol. 14, no. 4, pp. 533-535, 1980.

[4] R. Z. Legeros, L. M. Silverstone, G. Daculsi, and L. M. Kerebel, "In vitro caries-like lesion formation in F-containing tooth enamel," Journal of Dental Research, vol. 62, no. 2, pp. 138 144, 1983.

[5] J. Shackelford, Bioceramics (Advanced Ceramics), Prentice Hall, New Jersey, NJ, USA, 1992.

[6] B. Ratner, D. Hoffman, F. Schoen, and J. Lemons, Biomaterials Science: An Introduction to Materials in Medicine, Academic press, San Diego, Calif, USA, 1996.

[7] A. H. Reddi, "Morphogenesis and tissue engineering of bone and cartilage: inductive signals, stem cells, and biomimetic biomaterials," Tissue Engineering, vol. 6, no. 4, pp. 351-359, 2000.

[8] J. P. Fisher and A. H. Reddi, Functional Topics in Tissue Engineering of Bone: Signals and Scaffolds, Topics in Tissue English, Edited by N. Ashama Ki and P. Ferreti, 2003.

[9] I. S. Kim and P. N. Kumta, "Sol-gel synthesis and characterization of nanostructured hydroxyapatite powder," Materials Science and Engineering B, vol. 111, no. 2-3, pp. 232-236, 2004.

[10] M. F. Cerera, J. Heinamaki, K. krogars, and C. Jorgensen Anna, "Solid-state and mechanical Properties of aqueous chitosan-amylose starch films plasticized with polyls," AAPS Pharmaceutical Science and Technology, no. 1, article 5, 2004.

[11] A. Lazaridou and C. G. Biliaderis, "Thermophysical properties of chitosan, chitosan-starch and chitosan-pullulan films near the glass transition," Carbohydrate Polymers, vol. 48, no. 2, pp. 179-190, 2002.

[12] F. Mano, D. Koniarova, and R. Reis, "Thermal properties of thermoplastic starch/synthetic polymer blends with potential biomedical applicability," Journal of Materials Science, vol. 14, no. 2, pp. 127-135, 2003.

[13] E. T. Baran, J. F. Mano, and R. Reis, "Starch-chitosan hydrogels prepared by reductive alkylation cross-linking," Journal of Materials Science, vol. 15, no. 7, pp. 759-765, 2004.

[14] T. Kokubo, H. M. Kim, M. Kawashita, and T. Nakamura, "Novel ceramics for biomedical applications," The Australian Ceramic Society, vol. 36, pp. 37-46, 2000.

[15] R. L. Reis, S. C. Mendes, A. M. Cunha, and M. J. Bevis, "Processing and in vitro degradation of starch/EVOH thermoplastic blends," Polymer International, vol. 43, no. 4, pp. 347352, 1997.

[16] R. L. Reis, A. M. Cunha, and M. J. Bevis, "Structure development and control of injection-molded hydroxylapatitereinforced starch/EVOH composites," Advances in Polymer Technology, vol. 16, no. 4, pp. 263-277, 1997.

[17] S. H. Pak and C. Caze, "Acid-base interactions on interfacial adhesion and mechanical responses for glass-fiber-reinforced low-density polyethylene," Journal of Applied Polymer Science, vol. 65, no. 1, pp. 143-153, 1997.

[18] Z. Demjen, B. Pukanszky, and J. Nagy, "Possible coupling reactions of functional silanes and polypropylene," Polymer, vol. 40, no. 7, pp. 1763-1773, 1999.

[19] M. L. Gaillard, J. van der Brink, C. A. van Blitterswijk, and Z. B. Luklinska, "Applying a calcium phosphate layer on $\mathrm{PEO} / \mathrm{PBT}$ copolymers affects bone formation in vivo," Journal of Materials Science, vol. 5, no. 6-7, pp. 424-428, 1994.

[20] J. I. Velasco, J. A. de Saja, and A. B. Martínez, "Crystallization behavior of polypropylene filled with surface-modified talc," Journal of Applied Polymer Science, vol. 61, no. 1, pp. 125-132, 1996.

[21] M. Tanoglu, S. H. McKnight, G. R. Palmese, and J. W. Gillespie, "Use of silane coupling agents to enhance the performance of adhesively bonded alumina to resin hybrid composites," International Journal of Adhesion and Adhesives, vol. 18, no. 6, pp. 431-434, 1998.

[22] W. Qiu, M. Kancheng, and H. Zeng, "Effect of macromolecular coupling agent on the property of PP/GF composites," Journal of Applied Polymer Science, vol. 71, no. 10, pp. 15371542, 1999.

[23] G. T. Hermanson, "Bioconjugate Techniques," Academic Press, San Diego, California, p. 116, 1996. 

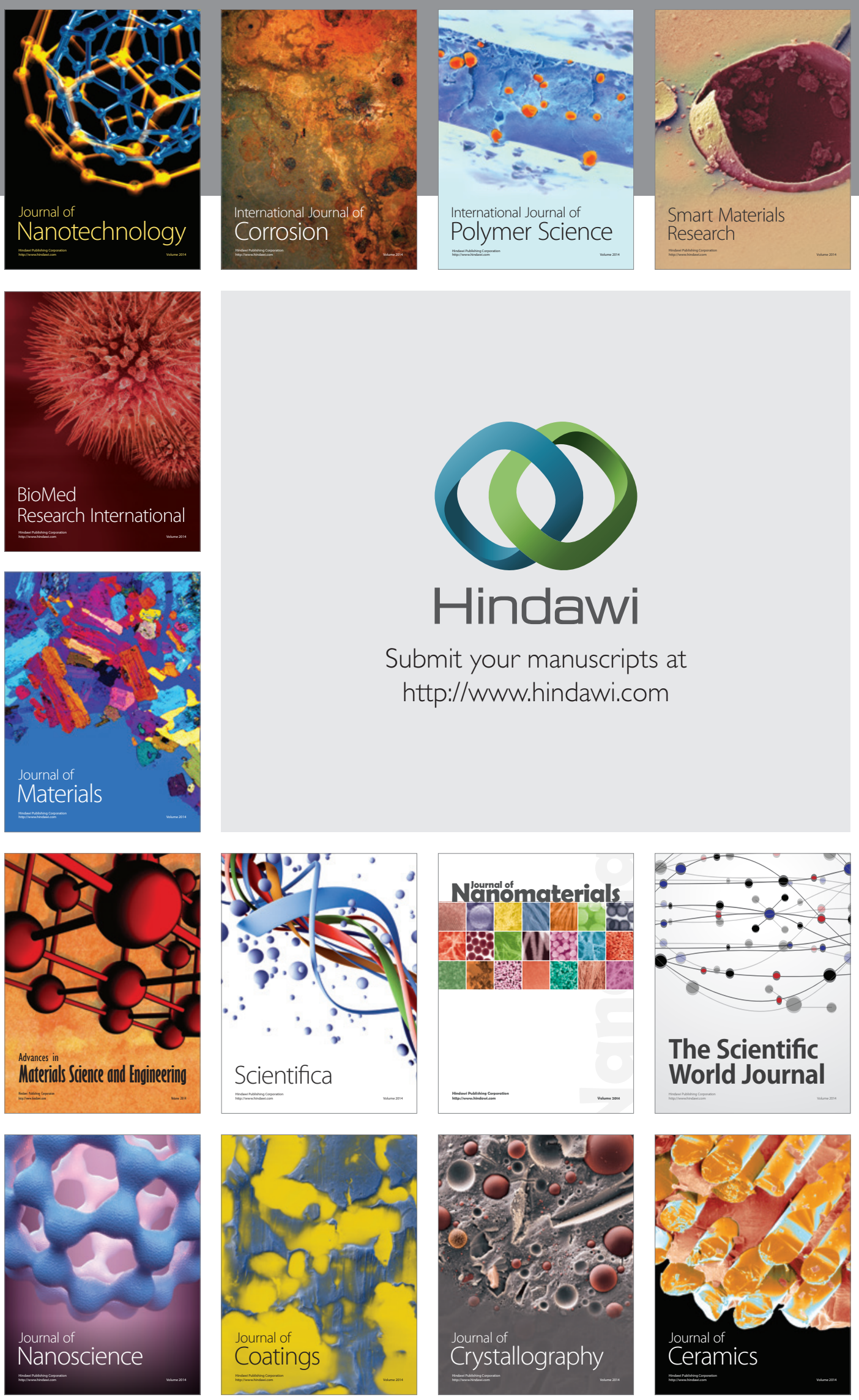

The Scientific World Journal

Submit your manuscripts at

http://www.hindawi.com

\section{World Journal}

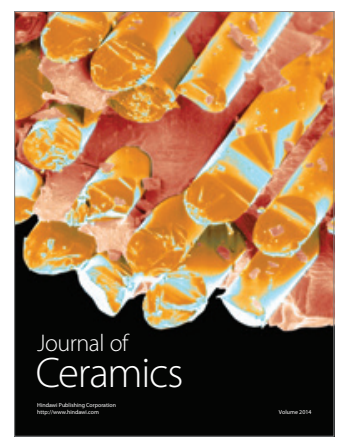

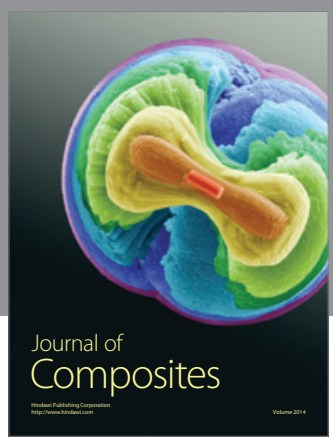
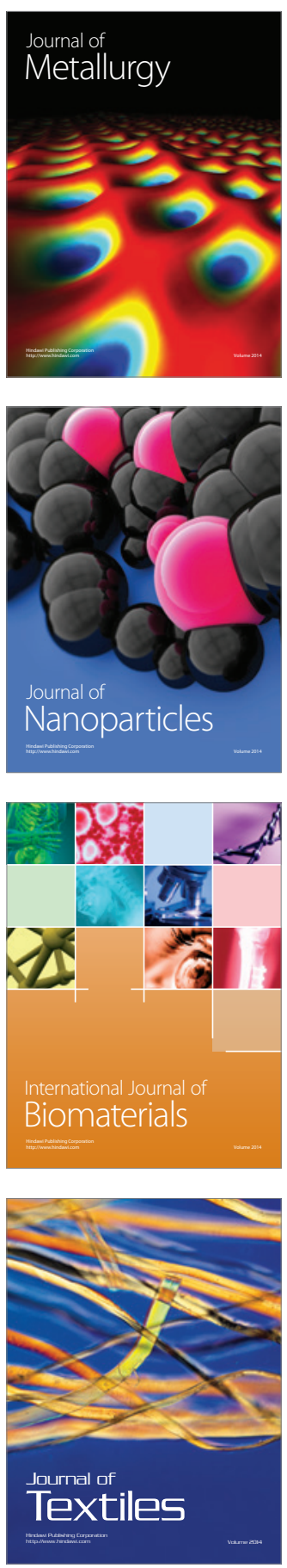